\title{
Linking ectomycorrhizal mushroom species richness and composition with dominant trees in a tropical seasonal rainforest
}

\author{
Ediriweera $A N{ }^{2,3,4}$, Karunarathna $\mathrm{SC}^{1,2,3,4}, \mathrm{Xu} \mathrm{J}^{1,2,4}{ }^{*}$, Bandara SMGS ${ }^{7}$, \\ Gamage $A^{6}$, Schaefer $D A^{1,2}$
}

${ }^{1}$ CAS Key Laboratory for Plant Diversity and Biogeography of East Asia, Kunming Institute of Botany, Chinese Academy of Sciences, Kunming 650201, Yunnan, China

${ }^{2}$ Centre for Mountain Ecosystem Studies, Kunming Institute of Botany, Chinese Academy of Sciences, Kunming 650201, China

${ }^{3}$ Center of Excellence in Fungal Research, and School of Science, Mae Fah Luang University, Chiang Rai 57100, Thailand

${ }^{4}$ World Agroforestry Centre, East and Central Asia, 132 Lanhei Road, Kunming 650201, China

${ }^{5}$ Department of Biosystems Technology, Faculty of Technology, University of Ruhuna

${ }^{6}$ Department of Economics, Faculty of Humanities and Social Sciences, University of Ruhuna, Sri Lanka

${ }^{7}$ Department of Mathematics, Faculty of Science, University of Ruhuna

Ediriweera AN, Karunarathna SC, Xu J, Bandara SMGS, Gamage A, Shaefer DA 2020 - Linking ectomycorrhizal mushroom species richness and composition with dominant trees in a tropical seasonal rainforest. Studies in Fungi 5(1), 471-484, Doi 10.5943/sif/5/1/28

\begin{abstract}
Vegetation, elevation gradient and soil temperature are considered as major drivers of ECM fungi species richness. ECM sporocarps were collected during rainy seasons for two years to study the link between the distribution of ECM mushrooms with Castonopsis echinocarpa, Parashorea chinensis, and Pittosporopsis kerrii with varying elevations and soil temperatures, in a tropical rain forest Xishuangbanna, Yunnan, China. For each tree species, 60 trees of approximately the same size were selected, where half of them were growing at higher elevation levels and the rest at lower levels. The highest total counts of ECM fungi, as well as the highest species richness were produced by $P$. chinensis followed by $C$. echinocarpa and $P$. kerrii. Highest species richness was shown in September by $P$. chinensis, while $P$. kerrii trees had the lowest count of mushrooms across rainy seasons. Species of Boletales were recorded with highest species richness followed by species of order Agaricales around both C.echinocarpa and P.chinensis. ECM fungi count declined with increased elevation. Furthermore, fungi species richness increased positively with increased soil temperature in a tropical seasonal rainforest.
\end{abstract}

Key words - Ectomycorrhizal fungi - elevation - soil temperature - diversity - Xishuangbanna

\section{Introduction}

Ectomycorrhizal (ECM) fungi are considered important and diverse symbiotic organisms that significantly enhance host plant nutrition. ECM macrofungi play a significant role in maintaining biodiversity, decomposition, nutrient transportation and carbon cycling (Hobbie et al. 1999, Lin et al. 2015). ECM symbiosis has been recorded in both temperate and tropical forests. In tropical forests ECM symbiosis is considered as rare, but recorded from many tropical forests (Ediriweera et al. 2020, Corrales et al. 2018). ECM plant species in tropical rainforests occur in low densities 
with patchy distributions in a plant community dominated by arbuscular mycorrhizal plants (Smith et al. 2013).

Trees establish associations with ectomycorrhizal (ECM) fungi, whose diversity can approach 100 mushroom species within a single forest (Dickie et al. 2002, Courty et al. 2008, Smith \& Read 2008). ECM mutualism is necessary for the growth of some native plant species, as nearly $90 \%$ of roots of some tree species are colonized by ECM fungi (Visser 1995). Despite this, little is known about what manages the community structures and distribution of root-associated mushrooms in forest systems (Leake 2001, Lilleskov et al. 2004). The manifestation of root-associated fungi may depend on different soil characteristics (temperature, moisture, nutrient availability) and the existence of favorable host plants (Taylor \& Bruns 1999, Erland \& Taylor 2002, Hillebrand 2004, Lentendu et al. 2011, Bahram et al. 2012, Tedersoo et al. 2014a).

Plant distribution alongside soils, temperature and precipitation, play the strongest roles in determining the underground diversity of root-associated fungi and many ECM fungi can colonize a vast range of plant species (Trappe 1977, Burke et al. 2009, Tedersoo et al. 2014 a,b), especially those belonging to Russulaceae and Thelephoraceae families (Horton \& Bruns 2002, Izzo et al. 2005, Tedersoo et al. 2008). Additionally, certain ECM fungi are uniquely associated with specific tree host species (e.g. species of Suillus and Rhizopogon are unique to tree species belonging to the family Pinaceae) (Kretzer et al. 1996, Kretzer \& Bruns 1999). Topography is a major proximate factor for measuring spatial distribution patterns in plant and mushroom species compositions (Costa et al. 2005, Bohlman et al. 2008). Topography is strongly linked to microhabitat gradients across soil water and nutrient availability at local scales (Balvanera et al. 2012.

Many studies have been carried out investigating the effects of influential factors on the distribution of soil biota (Zhang et al. 2010, Kuszegi et al. 2015, Luo et al. 2016). Until now, however, the collective interaction of factors like temperature and elevation on the distribution of ECM fungi across different vegetation in tropical forests has been overlooked. Therefore, this study presents research findings carried out on macrofungi identified in a seasonal tropical rainforest in Xishuangbanna Prefecture, Yunnan Province, China. The objective of the study was to determine the affinity of ECM fungi with tree species. Furthermore, we aim to investigate the potential effects of tree species, soil temperature and elevation on the richness and composition of ECM fungi associated with these trees. Additionally, we hypothesized that ECM fungi species richness changes in accordance with elevation and soil temperature.

\section{Materials \& methods}

\section{Study site}

The seasonal tropical rainforest in Xishuangbanna is one of the most species-rich forest ecosystems in China (Cao \& Zhang 1997, Lan et al. 2012) and is listed as a biodiversity hotspot. The site contains over 5000 species of vascular plants, comprising $16 \%$ of the total plant diversity in China and plays a critical role in global biodiversity conservation (Cao et al. 2008).

The site Xishuangbanna Tropical Seasonal Rainforest Dynamics Plot (XTRDP) was established in a $P$. chinensis forest at $101^{\circ} 34^{\prime} 26^{\prime \prime} \sim 101^{\circ} 34^{\prime} 47^{\prime \prime}$ E, $21^{\circ} 36^{\prime} 42^{\prime \prime} \sim 21^{\circ} 36^{\prime} 58^{\prime \prime} \mathrm{N}$, where the forest features a canopy 40 60 m high, with three distinct tree layers, a shrub and herbaceous layer. Plot elevation ranged from 709.27 to $869.14 \mathrm{~m}$ above sea level and the point of highest elevation was in the northwest area of the plot (Cao et al. 2008).

After establishing a 20-ha permanent plot, fieldwork included topographical mapping, corner post setting, tree tagging and an initial tree census, all of which began in April 2006 and were completed in June 2007, paving the path for a number of further studies and research on tropical rain forests. Major research has focused on the effects of climatic factors, tree species diversity in tropical forest vegetation, litterfall dynamics, soil dynamics, hydrological effects, forest structures, biogeographical studies and studies on biodiversity changes. With different studies (Ediriweera et al. 2020) initiated in 2014, we explored macrofungal diversity in XTRDP. 


\section{Experimental design}

For the experiment, two elevation levels were considered for the study as site 1 and site 2 where site 1 was $<760 \mathrm{~m}$ of elevation and site 2 with elevation $>760 \mathrm{~m}$. Based on abundance and tree type trees of Castonopsis echinocarpa, Parashorea chinensis and Pittosporopsis kerrii trees with $10 \mathrm{~cm}$ DBH (Diameter at Breast Height) were selected using a random sampling method. For each tree species, 60 trees were selected in total, with 30 trees of each species for each site. The region of each tree with $10 \mathrm{~cm}$ DBH was painted red to facilitate identification and each tree was tagged with a unique code. Fungi were collected once every five days within a $1 \mathrm{~m}$ radius originating from the $10 \mathrm{~cm} \mathrm{DBH}$ point of each tree during both rainy seasons where each season consisted of three months (August to October). Descriptions were made of collected fungi based on morphological characteristics and then fungi were dried in a portable dryer at $40^{\circ} \mathrm{C}$ for $24-48$ hours before being sealed in Ziploc plastic bags containing silica gel as a desiccant. Dried specimens were separated and data about collected fungi were entered in a table created in MS-Excel. Soil temperature was measured weekly using CE IP65 Pen Type Digital Soil Thermometer.

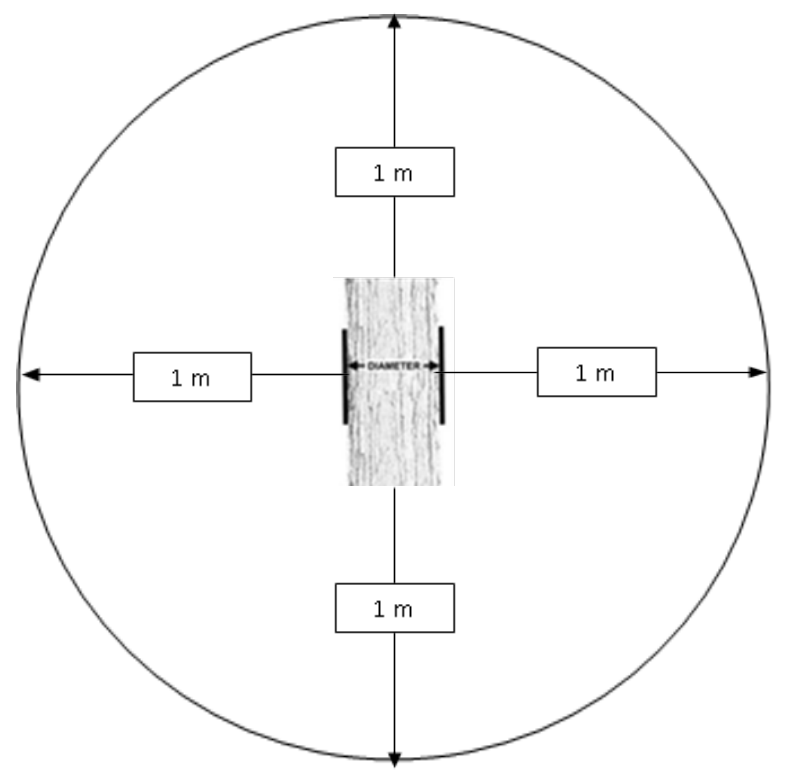

Fig. 1 - Considered area of a tree for mushroom collection

\section{Sporocarp Identification}

Macrofungi collected from the study area were returned to the laboratory and examined. Apparent macromorphological characteristics such as colour, shape and size of the macrofungi cap, stipe, gills and other facets such as odor, taste, color changes and habitat were annotated. Spore prints were made to determine the colour of the basidiospores, which were then used for measurements. Guide books, monographs (Corner 1966, Guzman 1983, Phillips 1981, Moser 1983, Arora 1986) journal articles (Das et al. 2013, Itoo et al. 2013, Ovrebo \& Baroni 2007, He et al. 2012) and online resources (http://www.indexfungorum.org, https://www.mushroomexpert.com) were used to identify the specimens up to species level and others to genus level. The taxonomic classification of species was based on Kirk et al. 2008, while Index Fungorum (2017) was used as the source of fungal nomenclature. After examination of specimens, they were dried in a portable food dryer for $24-32$ hours at $35^{\circ} \mathrm{C}$ and sealed separately in plastic bags.

\section{Compilation of data}

Collected data including tree number, number of macrofungi collected from each tree and names of species collected from each throughout the wet season were recorded separately. Three different codes were used for labeling the trees species: CE for C. echinocarpa, PC for P. chinensis and PK for P. kerrii. For the easy identification of trees, numbers from 1 to 60 were assigned (e.g. 
PC1, CE1, PK 1). Statistical analysis was performed with statistical software SPSS (Statistical Package for Social Sciences).

\section{Data analysis}

For data analysis, we used ANOVA Random Complete Block Design (RCBD), considering two different elevation levels as blocking factors, to analyze species richness across two different elevation levels. For multiple comparisons of three tree species and time of collecting season (Month) we applied Turkey s test and Dunnet s test. The Pearson correlation coefficient (R) was used to determine correlation between total number of mushroom species with soil temperature variation and along an elevation gradient.

\section{Results}

Counts of ECM fungi species collected in August, September and October in two consecutive seasons were 21, 45 and 6 with relevance to Castonopsis echinocarpa, Parashorea chinensis and Pittosporopsis kerrii which shows a significant difference at least between two vegetation types where $\mathrm{P}<0.05$. The species richness of ECM fungi in upper elevation level and lower elevation level was significant different with each level where $\mathrm{P}<0.05$ and the species richness of ECM fungi in August, September and October was significantly different. The variation of count of ECM fungi species with relevance to both month and elevation was significantly different and obtained results are shown in table below (Table 1).

Table 1 Effects on species richness of ECM fungi with relevance to different factors

\begin{tabular}{llllll}
\hline Source & $\begin{array}{l}\text { Type III some of } \\
\text { squares }\end{array}$ & df & Mean square & F & significance \\
\hline ECM Species & 6374.978 & 2 & 3187.489 & 579.732 & .000 \\
Elevation & 2587.267 & 1 & 2587.267 & 470.465 & .000 \\
Month & 1391.811 & 2 & 695.906 & 126.569 & .000 \\
Species * elevation & 554.711 & 2 & 277.356 & 50.445 & .000 \\
Species * month & 780.111 & 4 & 195.028 & 35.471 & .000 \\
Species * elevation * & 2870.067 & 4 & 31.878 & 5.798 & .000 \\
month & & & & & \\
\hline
\end{tabular}

Among the values of species richness associated with $C$. echinocarpa, $P$. chinensis and $P$. kerrii the highest species richness was recorded from $P$. chinensis with a 45 mushroom species where it is significantly higher $(\mathrm{P}<0.05)$ compared to C. echinicarpa and P. kerri. C. echinocarpa was recorded with 21 ECM fungi species where it was significantly different compared to $P$. kerrii $(\mathrm{P}<0.05)$ (Table 2).

Table 2 Multiple comparisons for ECM species richness between host tree species

\begin{tabular}{lllll}
\hline Host tree species & Host tree species & $\begin{array}{l}\text { Mean } \\
\text { difference }\end{array}$ & $\begin{array}{l}\text { Standard } \\
\text { error }\end{array}$ & Significance \\
\hline Castonopsis & Parashorea chinensis & -3.22 & .247 & .000 \\
echinocarpa & Pittosporopsis kerrii & 5.12 & .247 & .000 \\
Parashorea chinensis & Castonopsis echinocarpa & 3.22 & .247 & .000 \\
& Pittosporopsis kerrii & 8.34 & .247 & .000 \\
Pittosporopsis kerrii & Castonopsis echinocarpa & -5.12 & .247 & .000 \\
& Parashorea chinensis & -8.34 & .247 & .000 \\
Parashorea chinensis & Castonopsis echinocarpa & 3.22 & .247 & 1.000 \\
Pittosporopsis kerrii & Castonopsis echinocarpa & -5.12 & .247 & .000 \\
\hline
\end{tabular}


With relevance to time of rainy season the species count of ECM fungi varies in August, September and October. The highest species count has been recorded in August with relevance to all three vegetation types where $\mathrm{P}<0.05$.

Table 3 Multiple comparisons between time periods (Month) for the effect on ECM species richness

\begin{tabular}{lllll}
\hline Month & Month & Mean difference & Standard error & Significance \\
\hline August & September & 3.84 & .247 & .000 \\
& October & 2.64 & .247 & .000 \\
September & August & -3.84 & .247 & .000 \\
& October & -1.21 & .247 & .000 \\
October & August & -2.64 & .247 & .000 \\
& September & 1.21 & .247 & .000 \\
August & October & 2.64 & .247 & 1.000 \\
September & October & -1.21 & .247 & .000 \\
\hline
\end{tabular}

The total species richness of ECM fungi in lower elevation level and upper elevation level in XTRDP during both collection seasons, the lower elevation level bears highest species richness in XTRDP where $\mathrm{P}<0.05$.

Table 4 Pairwise comparison of ECM species richness at two elevation levels

\begin{tabular}{lllll}
\hline Elevation & Elevation & Mean difference & Standard error & Significance \\
\hline Upper & lower & -4.378 & .202 & .000 \\
\hline
\end{tabular}

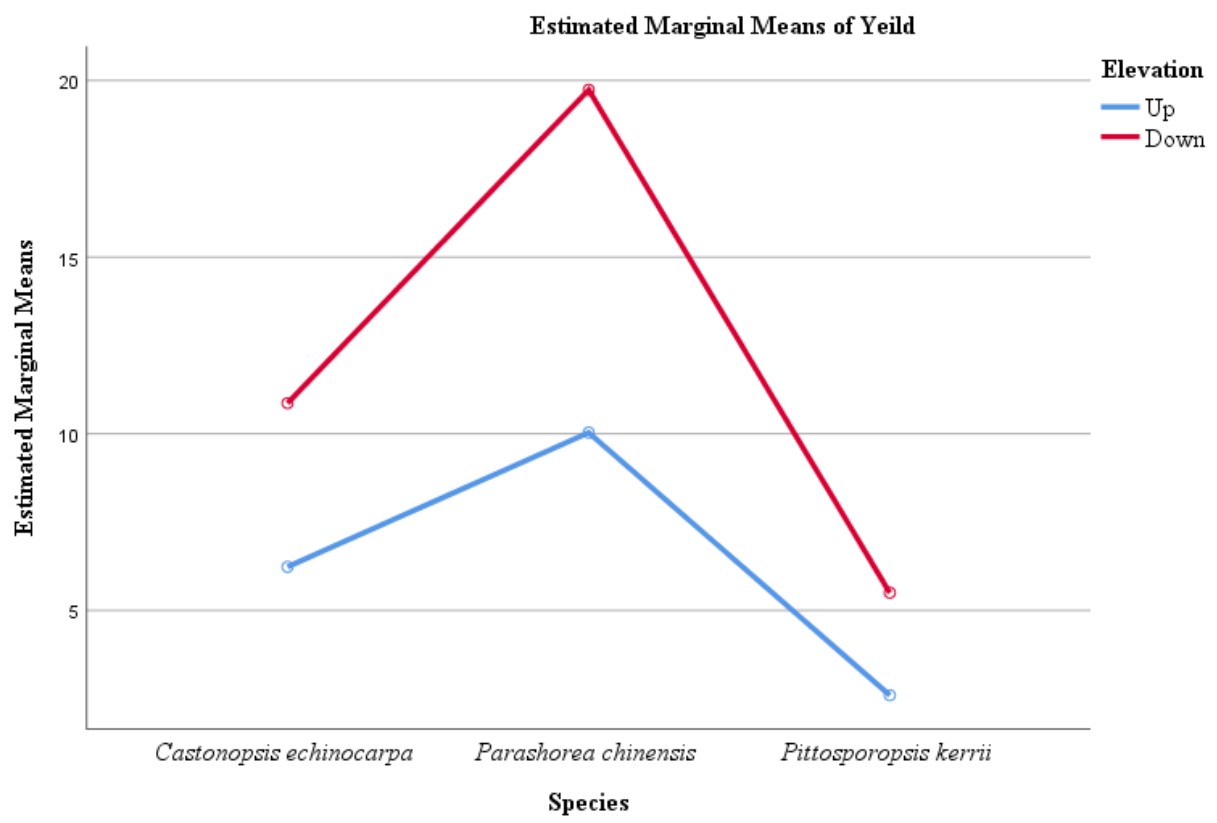

Fig. 2 - Variation of ECM mushroom species richness in lower and upper elevation in XTRDP

The highest count of mushroom species were recorded from order Boletales, Agaricales and Russulales from $P$. chinensis followed by $C$. echinocarpa. Least counts were recorded by $P$. kerrii. An equal number of species were represented by order Gomphales from $P$. chinensis and $C$. echinocarpa whilst equal number of species were produced by order Cantharellales from $C$. echinocarpa and P. kerrii. Order Cantharellales, Gomphales and Thelephorales were equally presented in association with $P$. kerrii (Fig. 3). 


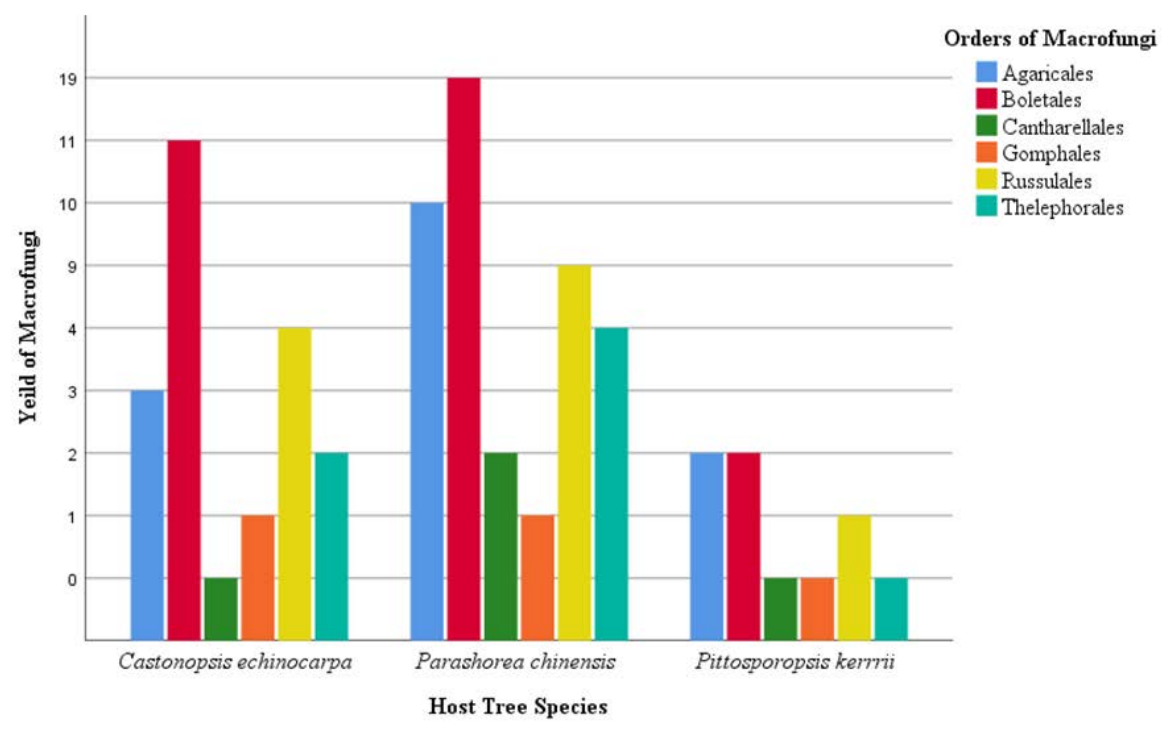

Fig. 3 - Number of ECM mushroom species yielded from different Orders

Among the ECM species associated with C. echinocarpa, site 1 was dominated with fungi belong to order Agaricales and Russulales with 2 and 4 species respectively whilst site 2 was rich with species of Boletales and Thelephorales (Table 5). Seven ECM species have been found common to both sites in association with $C$. echinocarpa. In association with $P$. chinensis, site 1 was dominated with species of Agaricales (9 species), Russulales ( 7 species) and some species of Boletales while few ECM species of Cantharellales and Gomphales too were reported. In site 2, most recorded species were from Boletales with 7 species while 4 species were recorded from Thelephorales. ECM association with $P$. kerrii was recorded as very poor.

Lactarius piperatus, Gyroporus castaneus, Thelephora terrestris, Thelephora palmate, Strobilomyces strobilaceus, Suillus luteus, Ramaria botrytis and Russula delica were common to both C. echinocarpa and P. chinensis. Laccaria laccata, Boletus badius and Amanita vaginata were common to all host tree species while Suillus grevillei was common to P. chinensis and P. kerrii. Russula albida was the only recorded as common for C. echinocarpa and P. kerrii.

The total count of ECM fungi species produced in August, September and October in both seasons were significantly negatively correlated with elevation gradient $(\mathrm{R}=-0.499 ; \mathrm{P}<0.05)$ (Fig. 3). The correlation between ECM mushroom species richness with of $C$. echinocarpa and $P$. chinensis show strong significant negative correlation $\left(\mathrm{R}^{2}=-0.832 ; \mathrm{P}<0.05, \mathrm{R}^{2}=-0.699 ; \mathrm{P}<0.05\right)$ and $P$. kerrii show moderate negative correlation between ECM species richness with elevation $\left(\mathrm{R}^{2}\right.$ $=-0.533 ; \mathrm{P}<0.05)$

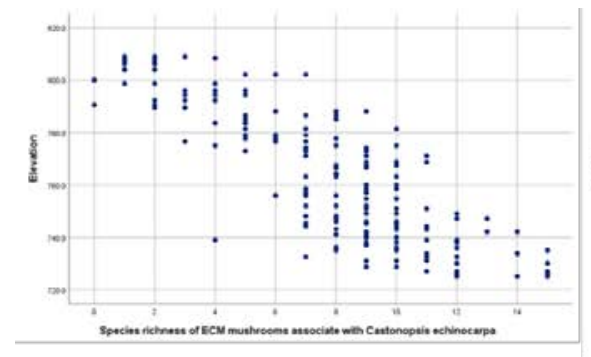

Fig 04

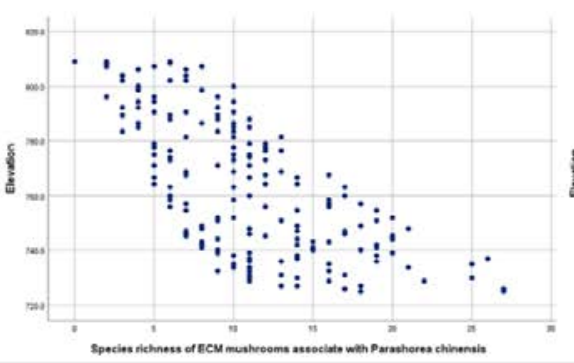

(b)

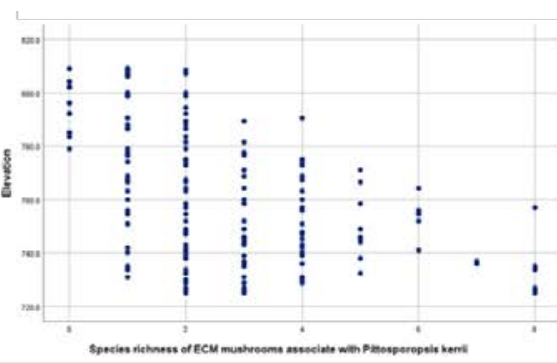

(c)

Fig. 4 - Correlation of ECM fungi species richness associate with (a) C. echinocarpa, (b) P. chinensis and (c) P. kerrii with elevation gradient 
Table 5 ECM fungi species recorded with relevance to each tree species in each site

\begin{tabular}{|c|c|c|c|c|}
\hline Host tree species & Order & Site 1 & Site 2 & Common species to both sites \\
\hline \multirow[t]{4}{*}{ Castonopsis echinocarpa } & Agaricales & $\begin{array}{l}\text { Cortinarius iodes } \\
\text { Amanita vaginata }\end{array}$ & & Laccaria laccata \\
\hline & Boletales & Strobilomyces strobilaceus & $\begin{array}{l}\text { Imleria badia } \\
\text { Boletus sinoaurantiacus } \\
\text { Boletus aereus } \\
\text { Xerocomellus zelleri }\end{array}$ & $\begin{array}{l}\text { Gyroporus castaneus } \\
\text { Hortiboletus rubellus } \\
\text { Suillus luteus } \\
\text { Butyriboletus floridanus } \\
\text { Suillus cavipes } \\
\text { Sutorius eximius }\end{array}$ \\
\hline & $\begin{array}{l}\text { Gomphales } \\
\text { Russulales }\end{array}$ & $\begin{array}{l}\text { Ramaria botrytis } \\
\text { Russula delica } \\
\text { Russula cyanoxantha } \\
\text { Lactifluus neuhoffii } \\
\text { Russula albida }\end{array}$ & & \\
\hline & Thelephorales & & $\begin{array}{l}\text { Thelephora palmata } \\
\text { Thelephora terrestris }\end{array}$ & \\
\hline \multirow[t]{3}{*}{ Parashorea chinensis } & Agaricales & $\begin{array}{l}\text { Cortinarius orellanosus } \\
\text { Cortinarius fulviconicus } \\
\text { Pseudosperma rimosum } \\
\text { Laccaria amethystina } \\
\text { Amanita flavorubescens } \\
\text { Inocybe geophylla } \\
\text { Amanita rubrovolvata } \\
\text { Hygrophorus discoxanthus } \\
\text { Amanita vaginata }\end{array}$ & & Laccaria laccata \\
\hline & Boletales & $\begin{array}{l}\text { Paxillus involutus } \\
\text { Suillus granulatus } \\
\text { Strobilomyces strobilaceus } \\
\text { Suillus grevillei } \\
\text { Astraeus hygrometricus }\end{array}$ & $\begin{array}{l}\text { Butyriboletus brunneus } \\
\text { Boletopsis grisea } \\
\text { Boletellus emodensis } \\
\text { Imleria badia } \\
\text { Boletus shiyong } \\
\text { Phlebopus portentosus } \\
\text { Pulveroboletus ravenelii }\end{array}$ & $\begin{array}{l}\text { Caloboletus radicans } \\
\text { Gyroporus castaneus } \\
\text { Suillus luteus } \\
\text { Xerocomellus chrysenteron } \\
\text { Suillus placidus } \\
\text { Caloboletus calopus } \\
\text { Caloboletus firmus }\end{array}$ \\
\hline & Cantharellales & $\begin{array}{l}\text { Cantharellus vaginatus } \\
\text { Cantharellus appalachiensis }\end{array}$ & & \\
\hline
\end{tabular}


Table 5 Continued.

\begin{tabular}{|c|c|c|c|c|}
\hline Host tree species & Order & Site 1 & Site 2 & Common species to both sites \\
\hline & Gomphales & Ramaria botrytis & & \\
\hline & Russulales & Russula virescens & & Lactifluus neuhoffii \\
\hline & & Russula maculata & & Russula crustosa \\
\hline & & Russula griseocarnosa & & \\
\hline & & Lactarius pyrogalus & & \\
\hline & & Russula claroflava & & \\
\hline & & Russula delica & & \\
\hline & & Russula violeipes & & \\
\hline & Thelephorales & & Thelephora palmata & \\
\hline & & & Thelephora terrestris & \\
\hline & & & Thelephora ganbajun & \\
\hline & & & Thelephora caryophyllea & \\
\hline \multirow[t]{4}{*}{ Pittosporopsis kerrii } & Agaricales & Amanita vaginata & & Laccaria laccata \\
\hline & Boletales & & & Suillus grevillei \\
\hline & Russulales & & & Imleria badia \\
\hline & & & & Russula albida \\
\hline
\end{tabular}

Note - ECM fungi species recorded from both sites but recorded $<10$ times from each site during the study were considered as common species to both sites

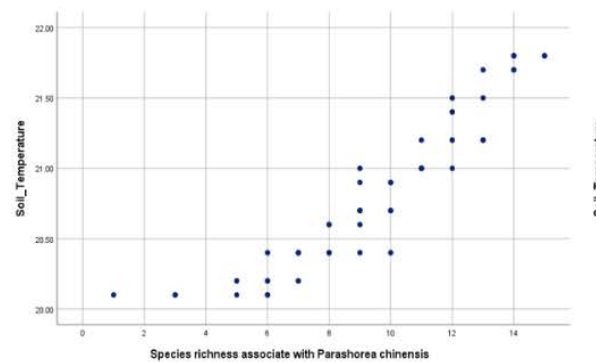

Fig 5

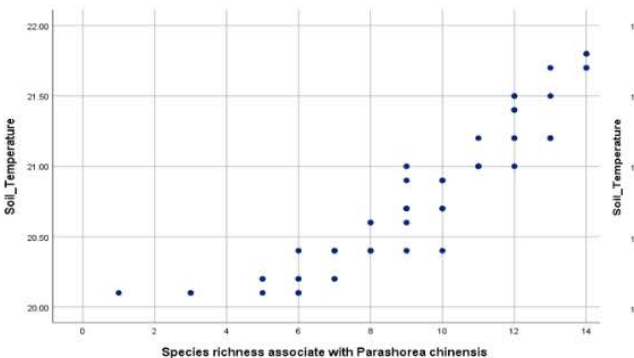

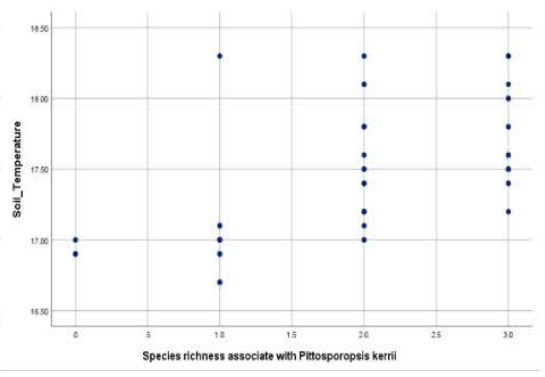

Fig. 5 - Correlation of ECM fungi species richness associate with (a) C. echinocarpa, (b) P. chinensis and (c) P. kerrii with soil temperature

The mean soil temperature associated with each tree species was found to be significantly different (Fig. 5). Along the elevation gradient, ECM fungi species richness was significantly positively correlated with soil temperature, however this effect was most pronounced in the plots surrounding C. echinocarpa and P. chinensis $\left(\mathrm{R}^{2}=0.908 ; \mathrm{P}<0.05, \mathrm{R}^{2}=0.937 ; \mathrm{P}<0.05\right)$, compared to P. kerrii $\left(\mathrm{R}^{2}=0.664 ; \mathrm{P}<0.05\right)$. 


\section{Discussion}

The results of our study show that the forest soils associated with Parashorea chinensis in the study area have a significantly greater species richness of ECM mushrooms than that of the areas surrounding Castonopsis echinocarpa and Pittosporopsis kerrii. These findings are in agreement with the work of Corrales et al. (2018) who reported that P.chinensis of family Dipterocarpaceae is the best host that forms ECM symbiosis in region of Southeast Asia. Smith et al. 2013 also reported that tree species within Dipterocarpaceae host large numbers of ECM fungi when compared against other tree families, such as Fagaceae. Singh (1966) reported evidence for the first time on species richness of ECM fungi associate with Dipterocarpaceae from Southeast Asia confirming 13 ECM associations from Malaysia and Hong too published species list of ECM fungi associated with Dipterocarpaceae in 1979 (De Alwis \& Abeynayake 1980, Alexander \& Hogberg 1986, Corrales et al. 2018).

ECM fungi species belong to Agaricales, Boletales, Russulales and Thelephorales has been reported from tropical rainforests in previous studies. Also it is reported that number of vital ECM associations are dominated across tropical environments despite the contrasting information reported on rareness of ECM linages in tropics (Tedersoo et al. 2009, 2012). ECM fungi belong to Amanita, Russula, Lactarius and Boletus report wide outbreak across tropical forests (Tedersoo et al. 2009, Tedersoo \& Smith 2013, Corrales et al. 2018). The Pantropical distribution shown by these species reveal that these ECM species are well adopted to tropical environment.

With relevance to all three tree species considered for the present study, count of ECM fungi species shows a noted decline with rising elevation. Species belong to order Agaricales and Russulales were dominated with higher species counts in site 1 (at lower elevations) while Boletus species were dominated in site 2 (at higher elevation) with affinity of C.echinocarpa and $P$. chinensis. This phenomenon of species decline at higher elevations was explained by Kernaghan \& Harper 2001, Jang \& Hur 2014 elaborating declining numbers of fungi species with increasing elevation in tropical rainforests (Kernaghan \& Harper 2001, Jang \& Hur 2014). The cause for growth variability of mushrooms at different elevation levels can be attributed to two likely factors. First would be a loss of nutrients from upslope to downslope areas, thus a higher nutrient collection in the lower elevation areas within the study site, and secondly, a change in soil moisture, with dryer soils being more prominent upslope. Within our study site, the soil moisture content was greatest in the lower elevations compared to higher elevations. Past studies have shown that soil moisture is key for the production of ECM fungi, as given by the studies of Ohenoja \& Metsanheimo 1982, Park et al. 1998, Hall et al. 1998.

The highest counts and levels of species richness of ECM fungi have been reported mid-rainy season over two years. This is well explained by Mani \& Cao 2016 presenting information on nutrient release in the tropical rainforests of Xishuangbanna. Mani \& Cao 2016 corroborate that soil nutrients do not increase immediately though litterfall is high in the late dry season. Drought precludes the function of decomposers to release large amounts of nutrients from the litter into the soil. From the beginning of the rainy season at the end of May, decomposition of litterfall surges, leading to increased soil nutrients in the middle of the rainy season, demonstrating a two month delay in nutrient release from litter to soil.

Among the species collected from the study, species belong to Boletales were counted as the highest around both $C$. echinocarpa and $P$. chinensis. This result has been proven with findings of Binder \& Hibbett 2007 where they revealed that Boletus species are well known to form associations with Dipterocarpaceae and Fagaceae. It is reported that Boletus species represent 18 $25 \%$ of all ECM fungi (Hawksworth et al. 1995) and in last twenty years number of Boletus species were recorded from tropical forests including novel species.

Among ECM fungi collected, Laccaria laccata showed higher abundance throughout the seasons without distinguishable differences at lower and higher elevations. Duponnois \& Garbaye 1991 reported similar finding on L. laccata showing that L. laccata, as a common ectomycorrhizal fungi in hard woods. It is further elaborated by Duponnois \& Garbaye 1991, Wilson et al. 2017, 
Ediriweera et al. 2020) explaining that L. laccata has potential of growing under vast types of ecosystems and varying edaphic factors.

In our study Thelephora species were identified as ECM species restricted only to site 2 in association with $C$. echinocarpa and $P$. chinensis where moisture content of low compared to lower elevation levels of forest. This finding agrees with results revealed by Koide et al. 2007 where he explained these species are known as drought tolerant species where it fruits in low moisture levels and identified as "contact type" mycorrhizae (Agerer 2001). Studies have revealed that Thelephora species show higher diversity though their counts are underestimated due to inconspicuous fruitbodies (Koljalg et al. 2000, Tedersoo et al. 2014b).

Our study reveals that ECM fungi species richness positively correlates with soil temperature, similar to reports made by Park et al. 1998, Swaty et al. 1998, Clemmensen et al. 2006, Gange et al. 2007. Both Clemmensen et al. 2006, Gange et al. 2007 demonstrated further the fruiting of ECM fungi being correlated to temperature where the colonization of ECM mushrooms is enhanced by increasing temperatures. Furthermore, Rygiewicz et al. 2000 have reported that increasing temperature can change species abundance of ECM fungi.

Species richness associated with $P$. kerrii were very lower than ECM fungi counts associated of fungi and number of fungal with $C$. echinocarpa and $P$. chinensis. In this study $P$. kerrii was considered for the experiment as a participant forms Arbuscular mycorrhizal (AM) symbiosis to compare fungi yields obtained from $C$. echinocarpa and $P$. chinensis. Since $P$. kerrii is an arbuscular mycorrhizal tree, even the lesser number of ECM fungi species recorded due to roots of nearby tree species form ECM symbiosis. Among the few ectomycorrhizal fungi species found to associate with P. kerrii, L. laccata is found to have the highest count with P. kerrii. However, previous studies have found no evidence of association between L. laccata and P. kerrii.

The idea of rareness and nonexistence of ECM fungi in tropics established based on results of previous studies on AM symbiosis despite reported evidence on ECM associations in tropics (Malloch et al. 1980, Corrales et al. 2018). Scattered records on tropical ECM fungi has been caused miscommunication and poor synthesis. However, the idea of nonexistence and rareness of ECM associations persisted throughout $20^{\text {th }}$ century. But with the easy access to tropical forests worldwide and improvement of different software tools have broadened the research opportunities from 1990s. Hence during last 20 years' time field of mycology was widened with novel information gathered on ECM associations in tropics challenging the persisting idea of rareness and nonexistence of ECM fungi in tropics (Heinemann 1954, Singer 1963, Corrales et al. 2018, Ediriweera et al. 2020).

Globally, attempts of conserving fungi lack far behind of animals and plants. Maintenance of long-term data and field information is the most crucial factor for conservation of ECM symbiosis. Present study, as many, just produce a snapshot on ECM diversity and levels of affinity of different ECM species to host plants. Hence, for the identification of ECM relationships with different hosts and their variation with environmental factors, the foremost step should be to assemble extensive ECM studies with identification, compiling both species, environmental factors and improved attentiveness on ECM fungi conservation.

\section{Conclusions}

Study site of the tropical rainforest is rich with more than 45 ECM species. The highest number of ECM fungi species are associated with $P$. chinensis, while the lowest affinity is shown with P. kerrii. Over the two-year period, ECM fungi species count peaked in September with respect to $P$. chinensis. Boletales species were shown to be dominated with both $C$. echinocarpa and $P$. chinensis followed by Order Agaricales while majority of Agaricales and Russulales were dominant in lower elevation levels. Boletus and Thelephora species found being restricted to upper elevations. Furthermore, species richness of ECM fungi species declined with increasing elevation and species richness levels increased positively with increasing soil temperature. Extensive studies analyzing ECM symbiosis could reveal the reasons behind the different distribution patterns, host specificity of ECM fungi and significance of the symbiosis in tropical forests. 


\section{Acknowledgements}

This research is supported by CGIAR-FTA Program and Key Research Program of the Ministry of Sciences and Technology (Grant No. 2017YFC0505101). Samantha C. Karunarathna would like to thank the CAS President's International Fellowship Initiative (PIFI) young staff under the grant number: 2020FYC0002 and the National Science Foundation of China (NSFC) under the project code 31851110759.

We acknowledge officers of XTRDP research center for extending their boundless cooperation for data collection and provision of information paving path for the scientific publication.

\section{References}

Agerer R. 2001 - Exploration types of ectomycorrhizae - a proposal to classify ectomycorrhizal mycelial systems according to their patterns of differentiation and putative ecological importance Mycorrhiza 11, 107-14.

Alexander IJ, Hogberg P. 1986 - Ectomycorrhizas of tropical angiosperm trees. New Phytologist 102, 541-549.

Arora D. 1986 - Mushroom Demystified: A Comprehensive Guide to the Fleshy Fungi. Ten Speed Press, Berkeley, California.

Bahram M, Põlme S, Koljalg U, Zarre S, Tedersoo L. 2012 - Regional and local patterns of ectomycorrhizal fungal diversity and community structure along an altitudinal gradient in the Hyrcanian forests of northern Iran. New Phytologist 193, 465-473.

Balvanera P, Uriarte M, Almeida-Lenero L, Altesor A et al. 2012 - Ecosystem service research in Latin America: The state of the art. Ecosystem Services 2, 56 -70.

Binder M, Hibbett DS. 2007 - Molecular systematics and biological diversification of Boletales. Mycologia 98, 971-981.

Bohlman SA, Laurance WF, Laurance SG, Nascimento HEM et al. 2008 - Importance of soils, topography and geographic distance in structuring central Amazonian tree communities. Journal of Vegetation Science 19, 863-874.

Burke DJ, Martin KJ, Rygiewicz PT, Topa MA. 2009 - Relative abundance of ectomycorrhizas in a managed loblolly pine (Pinus taeda L.) genetics plantation as determined through terminal restriction fragment length polymorphism (TRFLP) profiles. Canadian Journal of Botany 84, 924-932.

Cao M, Zhang J.1997 - Tree species diversity of tropical forest vegetation in Xishuangbanna, SW China. Biodiversity conservation 6, 995-1006. https://doi.org/10.1023/A:1018367630923.

Cao M, Zhu H, Wang H, Lan GY et al. 2008 - Xishuangbanna Tropical Seasonal Rainforest Dynamics Plot: Tree Distribution maps, Diameter tables and Species Documentation. Yunnan Science and Technology Press, Kunming.

Corner EJH. 1966 - A monograph of Cantharelloid fungi 1-255.

Corrales A, Henkel TW, Smith ME. 2018 - Ectomycorrhizal association in the tropicsbiogeography, diversity patterns and ecosystem roles. New Phytologist 220, 1076-1091.

Clemmensen KE, Michelsen A, Jonasson S, Shaver GR. 2006 - Increased ectomycorrhizal fungal abundance after long-term fertilization and warming of two arctic tundra ecosystems. New Phytologist 171, 391-404.

Costa FRC, Magnusson WE, Luizao RC. 2005 - Mesoscale distribution patterns of Amazonian understory herbs in relation to topography, soil and watersheds. Journal of Ecology 93, 863878.

Courty PE, Franc A, Pierrat JC, Garbaye J. 2008 - Temporal changes in the ectomycorrhizal community in two soil horizons of a temperate oak forest. Applications of Environmental Microbiology 74, 5792-5801.

Das SK, Mandal A, Datta AK, Gupta S et al. 2013 - Nucleotide sequencing and identification of some wild mushrooms. Scientific World Journal 2013, 1-7. 
De Alwis DP, Abeynayake K. 1980 - A survey of mycorrhizae in some forest trees of Sri Lanka. In: Mikola P, ed. Tropical mycorrhiza research. Oxford, UK: Clarendon Press 146-153.

Dickie IA, Bing X, Koide RT. 2002 - Vertical niche differentiation of ectomycorrhizal hyphae in soil as shown by TRFLP analysis. New Phytologist 156, 527-535.

Duponnois R, Garbaye J. 1991 - Techniques for controlled synthesis of Douglas-fir - Laccaria laccata ectomycorrhizal symbiosis. Annals of Forest Science 48, 641-650.

Ediriweera AN, Karunarathne SC, Xu J, Hyde KD et al. 2020 - Partial mutual exclusion of ectomycorrhizal and saprobic fungi in a tropical seasonal rainforest. Asian Journal of Mycology 3, 1-12.

Erland S, Taylor AFS. 2002 - Diversity of ecto-mycorrhizal fungal communities in relation to the abiotic environment 163-200. In van der Heijden MGA and Sanders I (ed.) Mycorrhizal ecology. Ecological studies 157 Springer, Heidelberg, Germany.

Gange AC, Gange EG, Sparks TH, Boddy L. 2007 - Rapid and recent changes in fungal fruiting patterns. Science 316, 71.

Guzman G. 1983 - The genus Psilocybe: a systematic revision of the known species including the history, distribution and chemistry of the hallucinogenic species. Beih. Nova Hedwigia 74, Cramer, Vaduz.

Hall IR, Lyon AJE, Wang Y, Sinclair L. 1998 - Ectomycorrhizal fungi with edible fruiting bodies 2. Boletus edulis. Economic Botany 52, 44-56.

Hawksworth DL, Kirk PM, Sutton BC, Pegler DN. 1995 - Ainsworth and Bisby's Dictionary of the Fungi 8th ed, CAB International, Wallingford.

He XL, Jiang ZD, Li TH, Shen YH. 2012 - Four new species of Entoloma s.l. (Agaricales) from southern China. Mycol Prog 11, 915-925.

Heinemann P. 1954 - Boletineae. Flore Iconographique des Champignons du Congo 3, 51-78.

Hillebrand H. 2004 - Generality of the Latitudinal Diversity Gradient. The American Naturalist 163, 192-211.

Hobbie EA, Macko SA, Shugart HH. 1999 - Interpretation of nitrogen isotope signatures using the NIFTE model. Oecologia 120, 405-415.

Horton TR, Bruns TD. 2001 - The molecular revolution in ectomycorrhizal ecology: peeking into the black-box. Molecular Ecology 10, 1855-1871.

Index Fungorum. 2017 - Available from http://www.indexfungorum.org/Names/Names.asp (Accessed March 2017).

Itoo ZA, Reshi ZA, Andrabi KI. 2013 - Characterization and identification of Russula firmula and Russula postiana from Himalayan moist temperate forests of Kashmir, African Journal of Biotechnology 12, 3643-3647.

Izzo A, Agbowo JA, Bruns TD. 2005 - Detection of plot-level changes in ectomycorrhizal communities across years in an old-growth mixed-conifer forest. New Phytologist 166, 619630.

Jang SK, Hur TC. 2014 - Relationship between climatic factors and the distribution of higher fungi in Byeonsanbando National Park, Korea. Mycobiology 42, 27-33.

Kernaghan G, Harper K. 2001 - Community structure of ectomycorrhizal fungi across an alpine/subalpine ecotone. Ecography 24, 181-188.

Kirk PM, Cannon PF, Minter DW, Stalpers JA. 2008 - Dictionary of the Fungi, 10th ed. CABI, Wallingford, UK.

Koide RT, Shumway DL, Xu B, Sharda J. 2007 - On temporal partitioning of a community of ectomycorrhizal fungi New Phytol. 174, 420-9.

Koljalg U, Dahlberg A, Taylor AFS, Larsson E et al. 2000 - Diversity and abundance of resupinate thelephoroid fungi as ectomycorrhizal symbionts in Swedish boreal forests. Molecular Ecology 9, 1985-1996.

Kretzer AM, Bruns TD. 1999 - Use of atp6 in fungal phylogenetics: an example from the Boletales. Molecular Phylogenitics and Evolution 13, 483-492. 
Kretzer AM, Li Y, Szaro T, Bruns TD. 1996 - Internal transcribed spacer sequences from 38 recognized species of Suillus sensu lato: phylogenetic and taxonomic implications. Mycologia 88, 776-785.

Kuszegi G, Siller I, Dima B, Takacs K et al. 2015 - Driversity of Macrofungal Species Composition in Temperate Forests West Hungary: Functional Groups Compared. Fungal Ecology 17, 69-83

Lan G, Zhu H, Cao M. 2012 - Tree species diversity of a 20-ha plot in a tropical seasonal rainforest in Xishuangbanna, southwest China. Journal of Forestry Research 17, 432-439.

Leake JR. 2001 - Is diversity of ectomycorrhizal fungi important for ecosystem function? New Phytologist 152, 1-3.

Lentendu G, Zinger L, Manel S, Coissac E et al. 2011 - Assessment of soil fungal diversity in different alpine tundra habitats by means of pyrosequencing. Fungal Diversity 49, 113-123.

Lilleskov EA, Bruns TD, Horton TR, Taylor DL, Grogan P. 2004 - Detection of forest stand level spatial structure in ectomycorrhizal fungal communities. FEMS Microbiology Ecology 49, 319-332.

Lin G, McCormack ML, Guo D. 2015 - Arbuscular mycorrhizal fungal effects on plant competition and community structure. Journal Ecology 103, 1224-1232.

Luo X, Karunarathna SC, Luo YH, Xu K et al. 2016 - Drivers of macrofungal composition and distribution in Yulong Snow Mountain, southwest China. Mycosphere 7, 727-740.

Malloch D, Pirozynski A, Raven P. 1980 - Ecological and evolutionary significance of mycorrhizal symbioses in vascular plants (a review). Proceedings of the National Academy of Sciences, USA 77, 2113-2118.

Mani S, Cao M. 2016 - Lagging effect of nutrient release in tropical seasonal forest soils in Xishuangbanna, southwest China. Journal of Tropical Forest Science 28, 217-226.

Moser M. 1983 - Keys to Agarics and Boleti (Polyporales, Boletales, Agaricales, Russulales) (English Transl. by S. Plant) Ed. Kibby G. Publ. R. Phillips, London, 535.

Ohenoja E, Metsanhelmo K. 1982 - Phenology and fruiting body production of macro-fungi in subarctic Finnish Lapland in Laursen GA and Ammirati JF, eds. Arctic and alpine mycology. Seattle: University of Washington Press, 371-389.

Ovrebo CL, Baroni TJ. 2007 - New taxa of Tricholomataceae and Entolomataceae (Agaricales) from Central America. Fungal Diversity 27, 157-170.

Park H, Kang H, Kim KS, Ryoo C. 1998 - Ectomycorrhizal mushrooms occurrence around the fairy ring of the Tricholoma matsutake at a pine mushroom forest. The Korean Journal of Mycology 6, 303-113.

Phillips R. 1981 - Mushrooms and other fungi of Great Britain and Europe, Pan Books

Rygiewicz PT, Martin KJ, Tuininga AR. 2000 - Morphotype community structure of ectomycorrhizas on Douglas fir (Pseudotsuga menziesii Mirb. Franco) seedlings grown under elevated atmospheric $\mathrm{CO}_{2}$ and temperature. Oecologia 124, 299-308.

Singh, KG. 1966 - Ectotrophic mycorrhiza in equatorial rain forests. Malaysian Forester 29, 13-18.

Singer R. 1963 - Oak mycorrhiza fungi in Colombia. Mycopathologia et mycologia applicata 20, 239-252.

Smith SE, Read DJ. 2008 - Mycorrhizal symbiosis, 787. Academic Press, Inc., London, United Kingdom.

Smith ME, Henkel TW, Uehling JK, Fremier AK et al. 2013 - The ectomycorrhizal fungal community in a Neotropical forest dominated by the endemic Dipterocarp Pakaraimaea dipterocarpacea. PLoS ONE 8, e55160.

Swaty RL, Gehring CA, Vanert M, Theimer TC et al. 1998 - Temporal variation in temperature and rainfall differentially affects ectomycorrhizal colonization at two contrasting sites. New Phytologist 139, 733-739.

Taylor DL, Bruns TD. 1999 - Community structure of ectomycorrhizal fungi in a Pinus muricata forest: minimal overlap between the mature forest and resistant propagule communities. Molecular Ecology 8, 1837-1850. 
Tedersoo L, Suvi T, Jairus T, Koljalg U. 2008 - Forest microsite effects on community composition of ectomycorrhizal fungi on seedlings of Picea abies and Betula pendula. Environmental Microbiology 10, 1189-1201.

Tedersoo L, May TW, Smith ME. 2009 - Ectomycorrhizal lifestyle in fungi: Global diversity, distribution, and evolution of phylogenetic lineages. Mycorrhiza 20, 217 - 63

Tedersoo L, Bahram M, Toots M, Diedhiou AG et al. 2012 - Towards global patterns in the diversity and community structure of ectomycorrhizal fungi. Molecular Ecology 21, 4160 4170.

Tedersoo L, Smith ME. 2013 - Lineages of ectomycorrhizal fungi revisited: foraging strategies and novel lineages revealed by sequences from belowground. Fungal Biology Reviews 27, 83-99.

Tedersoo L, Bahram M, Polme S, Koljalg U et al. 2014a - Global diversity and geography of soil fungi. Science 346, 1256688.

Tedersoo L, Bahram M, Ryberg M, Otsing E et al. 2014b - Global biogeography of the ectomycorrhizal/sebacina lineage (Fungi, Sebacinales) as revealed from comparative phylogenetic analyses. Molecular Ecology 23, 4168-4183.

Trappe JM. 1977 - Selection of fungi for ectomycorrhizal inoculation in nurseries. Annual Review of Phytopathology 15, 203-222.

Visser S. 1995 - Ectomycorrhizal fungal succession in jack pine stands following wildfire. New Phytologist 129, 389-401.

Wilson AW, Mueller GM, May TW. 2017 - Biogeography of the Ectomycorrhizal mushroom genus Laccaria. Biogeography of Mycorrhizal Symbiosis 230, 13.

Zhang Y, Zhou DQ, Zhao Q, Zhou TX, Hyde KD. 2010 - Diversity and ecological distribution of macrofungi in the Laojun Mountain region, southwestern China. Biodiversity and Conservation 19, 3545-3563. 